\title{
Thermal Properties of Ethyl Undecanoate and Ethyl Tridecanoate by Adiabatic Calorimetry
}

\author{
J. C. van Miltenburg* and H. A. J. Oonk
}

Chemical Thermodynamics Group, Debye Institute, Utrecht University, Padualaan 8, $3584 \mathrm{CH}$ Utrecht, The Netherlands

\begin{abstract}
The heat capacity of ethyl undecanoate was measured between $110 \mathrm{~K}$ and $365 \mathrm{~K}$; the compound crystallized in a metastable form, which recrystallized slowly to the stable crystalline state during heating. The triplepoint temperature of the stable form was found to be $(259.17 \pm 0.04) \mathrm{K}$, and the enthalpy of fusion was $(36.1 \pm 0.1) \mathrm{kJ} \cdot \mathrm{mol}^{-1}$. The purity calculated from the fractional melting curve was $97.5 \mathrm{~mol} \%$. The metastable form crystallized at $251.3 \mathrm{~K}$. The heat capacity of ethyl tridecanoate was measured between $175 \mathrm{~K}$ and $320 \mathrm{~K}$; the compound also crystallized in a metastable form, which recrystallized during heating to the stable form. The triple-point temperature was found to be $(272.4 \pm 0.1) \mathrm{K}$, and the enthalpy of fusion was $(40.7 \pm 0.1) \mathrm{kJ} \cdot \mathrm{mol}^{-1}$.
\end{abstract}

\section{Introduction}

In a recent publication, ${ }^{1}$ the available vapor pressure data of a series of methyl esters of the linear carboxylic acids were assessed. The consistency of the data was checked using the "arc-method", in which, by applying a linear contribution to the Clapeyron fit, irregularities in the data are easily spotted. When the vapor pressure measurements of van Bommel ${ }^{2}$ on the ethyl esters were checked, the measurements of the two compounds mentioned in the title clearly did not show the expected correlation. This was probably due to impurities in the samples. New samples, of the highest quality available, were purchased. A new series of vapor pressure measurements did not improve the results, so it was decided to measure the purity by adiabatic calorimetry. In this article, we present the heat capacity data and the enthalpies of fusion of the two ethyl esters, ethyl undecanoate and ethyl tridecanoate. No heat capacity data were found for these compounds in the literature.

\section{Experimental Section}

Ethyl undecanoate $\left(\mathrm{C}_{13} \mathrm{H}_{26} \mathrm{O}_{2}\right.$, CAR RN: 627-90-7) was purchased from Sigma; the stated purity was "approx. 99 mass \%". Ethyl tridecanoate $\left(\mathrm{C}_{15} \mathrm{H}_{30} \mathrm{O}_{2}\right.$, CAS RN: 28267-29-0) was purchased from Lancaster Synthesis; the stated purity was 99 mass \%. The compounds were used as received.

The calorimeter used for ethyl tridecanoate, CAL V (laboratory indication), has been described. ${ }^{3,4}$ Oxford Instruments calibrated the thermometer with a precision of $0.001 \mathrm{~K}$ using the ITS- $90^{5}$ temperature scale. The uncertainties of the heat capacity measurements were checked with $n$-heptane ${ }^{6}$ and synthetic sapphire ${ }^{7,8}$ and found to be within $0.2 \%$. Below $30 \mathrm{~K}$, the reproducibility of this calorimeter is about $1 \%$, between $30 \mathrm{~K}$ and $100 \mathrm{~K}$, it is ( 0.05 to 0.1$) \%$, and above $100 \mathrm{~K}$, it is $0.03 \%$. The calorimeter vessel was filled in a glovebox under a nitrogen atmosphere and evacuated for about $5 \mathrm{~min}$ before closing the measuring vessel. A helium pressure of about $1000 \mathrm{~Pa}$

\footnotetext{
* Corresponding author. E-mail: miltenb@chem.uu.nl.
}

was admitted before closing in order to promote the heat exchange within the vessel. Measurements were made in the intermittent mode using stabilization periods of about $600 \mathrm{~s}$ and heat input periods of about $500 \mathrm{~s}$. The temperature increase was generally about $2 \mathrm{~K}$ for each measurement outside the transition region.

For the measurements on ethyl undecanoate, CAL 8 was used. ${ }^{9}$ This calorimeter was specially designed for small samples and was used because only a limited amount of material was available. This calorimeter was described recently; it uses about $0.5 \mathrm{~g}$ of sample. The measurement on $n$-heptane and synthetic sapphire showed that the accuracy of the heat capacity measurements was on the order of $0.5 \%$ and for latent heat effects such as the enthalpy of fusion it was on the order of $0.2 \%$.

Ethyl undecanoate (molar mass $214.34 \mathrm{~g} \cdot \mathrm{mol}^{-1}$ ) was measured in CAL 8. About $0.5 \mathrm{~g}$ was used. The experimental data are given in Table 1 . First the sample was quickly cooled to about $140 \mathrm{~K}$, and a measurement was made to $300 \mathrm{~K}$. In this measurement, exothermic effects took place (Figure 1) between $200 \mathrm{~K}$ and $220 \mathrm{~K}$ and during the melting process between 255 and $259 \mathrm{~K}$, indicating the transition to the stable crystalline form. The sample was cooled again to $160 \mathrm{~K}$; this cooling was controlled by setting the control temperature of the shield regulation about $10 \mathrm{~K}$ below the vessel temperature without breaking the vacuum. The cooling curve is given in Figure 4. From this curve, it is clear that the compound crystallizes at $253.2 \mathrm{~K}$ with only a very small undercooling, implying that this temperature can also be taken as the melting temperature of the metastable form. This means that the double peak in the heat capacity curve given in Figure 2 is not caused by a solid-solid transition followed by melting, as it appears at first sight, but is caused by the melting of the metastable crystal form, whereas during the melting process recrystallization to the stable crystal form takes place. This recrystallization is slow and is not directly visible in the heat capacity curve but manifests itself in the positive temperature drift during the stabilization periods. After equilibrating for $36 \mathrm{~h}$ at $252 \mathrm{~K}$, a measurement to $257 \mathrm{~K}$ was made. No exothermic effects occurred, indicating that the 
Table 1. Experimental Data Series for Ethyl Undecanoate

\begin{tabular}{|c|c|c|c|c|c|c|c|c|}
\hline$T$ & $C_{p}$ & $\underline{H(T)-H(\text { start })}$ & $T$ & $C_{p}$ & $\underline{H(T)-H(\text { start })}$ & $T$ & $C_{p}$ & $H(T)-H($ start $)$ \\
\hline $\mathrm{K}$ & $\mathrm{J} \cdot \mathrm{K}^{-1} \cdot \mathrm{mol}^{-1}$ & $\mathrm{~J} \cdot \mathrm{mol}^{-1}$ & $\mathrm{~K}$ & $\mathrm{~J} \cdot \mathrm{K}^{-1} \cdot \mathrm{mol}^{-1}$ & $\mathrm{~J} \cdot \mathrm{mol}^{-1}$ & $\mathrm{~K}$ & $\mathrm{~J} \cdot \mathrm{K}^{-1} \cdot \mathrm{mol}^{-1}$ & $\mathrm{~J} \cdot \mathrm{mol}^{-1}$ \\
\hline \multicolumn{9}{|c|}{ series $1^{a}$} \\
\hline 139.88 & 207.52 & 8629 & 201.57 & 212.99 & 23385 & 253.80 & 14892 & 55259 \\
\hline 143.35 & 212.19 & 9347 & 204.69 & 161.31 & 23968 & 254.12 & 12654 & 59599 \\
\hline 146.22 & 216.66 & 9963 & 207.94 & 120.20 & 24425 & 255.70 & 480 & 62434 \\
\hline 149.10 & 220.22 & 10590 & 211.21 & 152.71 & 24869 & 257.82 & 2171 & 64633 \\
\hline 151.98 & 223.45 & 11231 & 214.35 & 206.94 & 25433 & 258.64 & 18871 & 68371 \\
\hline 154.87 & 227.20 & 11883 & 217.39 & 247.39 & 26121 & 259.44 & 2260 & 72131 \\
\hline 157.77 & 230.26 & 12544 & 220.36 & 278.18 & 26901 & 261.58 & 419.55 & 74286 \\
\hline 160.66 & 236.92 & 13219 & 223.29 & 297.94 & 27746 & 264.49 & 420.55 & 75509 \\
\hline 163.55 & 242.00 & 13912 & 226.21 & 309.76 & 28631 & 267.39 & 421.02 & 76732 \\
\hline 166.44 & 242.39 & 14613 & 229.11 & 318.55 & 29544 & 270.29 & 422.21 & 77953 \\
\hline 169.36 & 239.53 & 15314 & 232.01 & 328.11 & 30481 & 273.18 & 423.35 & 79176 \\
\hline 172.28 & 242.64 & 16018 & 234.90 & 342.23 & 31450 & 276.07 & 424.79 & 80399 \\
\hline 175.19 & 244.71 & 16727 & 237.78 & 363.87 & 32464 & 278.95 & 425.66 & 81623 \\
\hline 178.11 & 247.80 & 17445 & 240.62 & 402.06 & 33551 & 281.82 & 425.14 & 82843 \\
\hline 181.02 & 251.81 & 18176 & 243.39 & 477.14 & 34768 & 284.68 & 426.82 & 84063 \\
\hline 183.93 & 254.69 & 18912 & 246.01 & 650.51 & 36235 & 287.54 & 428.33 & 85284 \\
\hline 186.85 & 258.17 & 19659 & 248.31 & 1069 & 38174 & 290.39 & 429.39 & 86508 \\
\hline 189.76 & 261.13 & 20415 & 250.26 & 1451 & 40594 & 293.24 & 430.72 & 87732 \\
\hline 192.68 & 263.19 & 21180 & 251.84 & 2257 & 43440 & 296.08 & 431.60 & 88957 \\
\hline 195.60 & 260.74 & 21946 & 252.88 & 5347 & 46917 & 298.92 & 433.20 & 90185 \\
\hline 198.55 & 246.06 & 22694 & 253.45 & 10293 & 50961 & & & \\
\hline \multicolumn{9}{|c|}{ series $2^{b}$} \\
\hline 111.58 & 173.66 & 339 & 201.88 & 266.33 & 20194 & 258.71 & 48322 & 64790 \\
\hline 113.84 & 175.94 & 740 & 204.18 & 269.86 & 20811 & 258.78 & 41751 & 67845 \\
\hline 116.71 & 178.91 & 1248 & 206.47 & 268.45 & 21427 & 258.87 & 27850 & 70874 \\
\hline 119.57 & 181.88 & 1764 & 208.75 & 272.25 & 22043 & 259.64 & 994 & 73091 \\
\hline 122.42 & 185.27 & 2286 & 211.01 & 276.09 & 22664 & 261.33 & 414.49 & 74204 \\
\hline 125.29 & 187.91 & 2821 & 213.26 & 279.59 & 23289 & 263.28 & 418.61 & 75019 \\
\hline 128.15 & 190.48 & 3362 & 215.50 & 279.55 & 23916 & 265.23 & 419.66 & 75835 \\
\hline 131.02 & 194.47 & 3914 & 217.73 & 283.48 & 24543 & 267.18 & 419.56 & 76652 \\
\hline 133.86 & 198.69 & 4472 & 219.95 & 287.50 & 25177 & 269.12 & 420.55 & 77466 \\
\hline 136.66 & 198.56 & 5029 & 222.16 & 290.42 & 25814 & 271.06 & 421.01 & 78282 \\
\hline 139.44 & 201.64 & 5585 & 224.36 & 293.74 & 26456 & 272.99 & 421.34 & 79098 \\
\hline 142.19 & 204.69 & 6143 & 226.54 & 297.69 & 27101 & 274.93 & 422.40 & 79914 \\
\hline 144.90 & 207.94 & 6703 & 228.71 & 302.05 & 27752 & 276.86 & 423.50 & 80731 \\
\hline 147.59 & 211.29 & 7266 & 230.87 & 307.08 & 28409 & 278.79 & 424.54 & 81549 \\
\hline 150.26 & 213.75 & 7832 & 233.01 & 312.10 & 29073 & 280.72 & 424.74 & 82368 \\
\hline 152.89 & 217.30 & 8401 & 235.14 & 318.94 & 29745 & 282.65 & 425.25 & 83187 \\
\hline 155.51 & 220.97 & 8974 & 237.26 & 327.12 & 30428 & 284.57 & 425.82 & 84005 \\
\hline 158.10 & 224.09 & 9550 & 239.36 & 337.32 & 31125 & 286.49 & 426.92 & 84826 \\
\hline 160.67 & 229.12 & 10132 & 241.44 & 349.15 & 31839 & 288.42 & 427.56 & 85647 \\
\hline 163.21 & 233.25 & 10720 & 243.49 & 366.65 & 32574 & 290.34 & 427.60 & 86467 \\
\hline 165.73 & 236.15 & 11312 & 245.51 & 390.29 & 33339 & 292.25 & 429.47 & 87289 \\
\hline 168.24 & 230.57 & 11897 & 247.49 & 425.06 & 34147 & 294.17 & 430.48 & 88114 \\
\hline 170.74 & 232.17 & 12475 & 249.42 & 480.50 & 35017 & 296.09 & 431.30 & 88940 \\
\hline 173.23 & 234.76 & 13056 & 251.26 & 571.99 & 35982 & 298.00 & 431.45 & 89767 \\
\hline 175.70 & 236.78 & 13638 & 252.97 & 727 & 37090 & 299.92 & 432.30 & 90594 \\
\hline 178.15 & 239.40 & 14222 & 254.50 & 1039 & 38419 & 301.84 & 434.20 & 91424 \\
\hline 180.59 & 242.15 & 14809 & 255.75 & 1661 & 40066 & 303.75 & 436.09 & 92258 \\
\hline 183.01 & 244.19 & 15398 & 256.70 & 2825 & 42085 & 305.67 & 436.86 & 93094 \\
\hline 185.42 & 245.75 & 15987 & 257.35 & 4810 & 44446 & 307.58 & 437.94 & 93930 \\
\hline 187.81 & 248.17 & 16577 & 257.78 & 7790 & 47065 & 309.50 & 438.69 & 94769 \\
\hline 190.18 & 251.89 & 17171 & 258.08 & 11784 & 49851 & 311.41 & 439.51 & 95609 \\
\hline 192.55 & 256.43 & 17772 & 258.29 & 16860 & 52743 & 313.32 & 440.63 & 96451 \\
\hline 194.90 & 257.21 & 18376 & 258.44 & 23291 & 55703 & 315.24 & 441.69 & 97295 \\
\hline 197.24 & 257.78 & 18978 & 258.55 & 30126 & 58705 & 317.15 & 443.16 & 98144 \\
\hline 199.56 & 262.12 & 19583 & 258.64 & 38815 & 61737 & 319.06 & 444.40 & 98991 \\
\hline \multicolumn{9}{|c|}{ series $3^{c}$} \\
\hline 292.35 & 429.73 & 87323 & 318.35 & 443.44 & 98676 & 342.69 & 459.47 & 109665 \\
\hline 293.82 & 430.15 & 87954 & 320.22 & 444.36 & 99506 & 344.57 & 461.00 & 110530 \\
\hline 295.74 & 431.35 & 88781 & 322.09 & 445.90 & 100338 & 346.45 & 462.31 & 111399 \\
\hline 297.65 & 432.04 & 89606 & 323.96 & 447.60 & 101173 & 348.34 & 463.75 & 112271 \\
\hline 299.55 & 433.51 & 90429 & 325.83 & 448.49 & 102010 & 350.22 & 465.10 & 113147 \\
\hline 301.45 & 434.67 & 91253 & 327.70 & 449.50 & 102850 & 352.11 & 466.34 & 114027 \\
\hline 303.35 & 436.03 & 92077 & 329.57 & 450.40 & 103692 & 354.00 & 467.34 & 114910 \\
\hline 305.23 & 437.30 & 92902 & 331.44 & 451.66 & 104536 & 355.90 & 468.59 & 115797 \\
\hline 307.12 & 438.29 & 93727 & 333.31 & 453.33 & 105383 & 357.80 & 469.50 & 116687 \\
\hline 309.00 & 438.55 & 94551 & 335.19 & 455.41 & 106234 & 359.70 & 471.05 & 117581 \\
\hline 310.87 & 439.73 & 95375 & 337.06 & 456.14 & 107088 & 361.60 & 472.21 & 118479 \\
\hline 312.74 & 440.36 & 96198 & 338.94 & 456.81 & 107945 & 363.51 & 473.69 & 119381 \\
\hline 314.61 & 441.72 & 97023 & 340.81 & 458.35 & 108803 & 365.42 & 475.18 & 120288 \\
\hline 316.48 & 441.83 & 97849 & & & & & & \\
\hline
\end{tabular}

${ }^{a}$ Series 1: metastable crystal to the liquid phase. ${ }^{b}$ Series 2: annealed crystal to the liquid phase. ${ }^{c}$ Series 3 : liquid phase. 


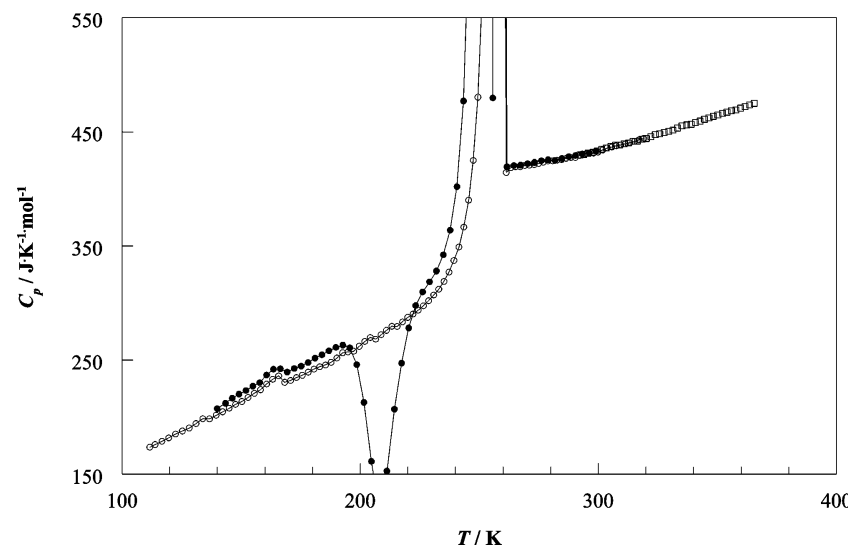

Figure 1. Experimental heat capacity data of ethyl undecanoate: -, first run; $\bigcirc$, second run after equilibration close to the melting point.

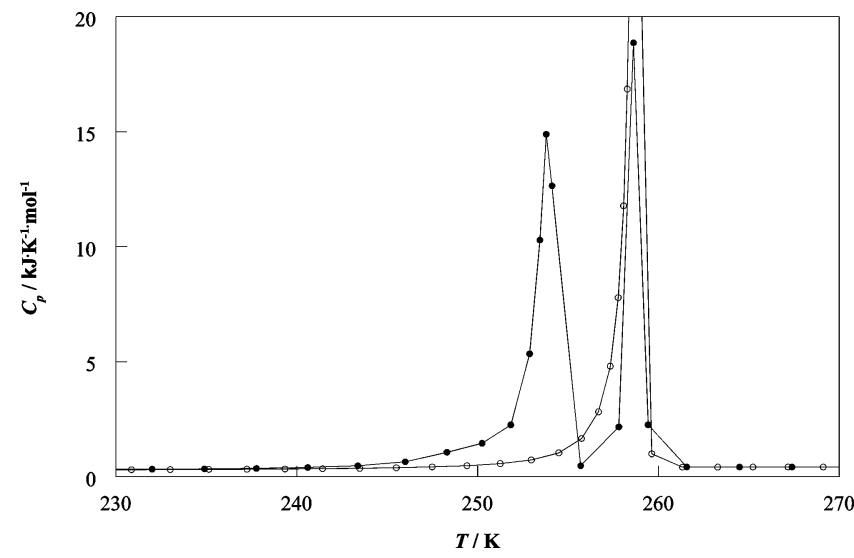

Figure 2. Enlarged view of Figure 1 around the melting point. In the first run, given by $\bullet$, the melting process takes place in two steps.

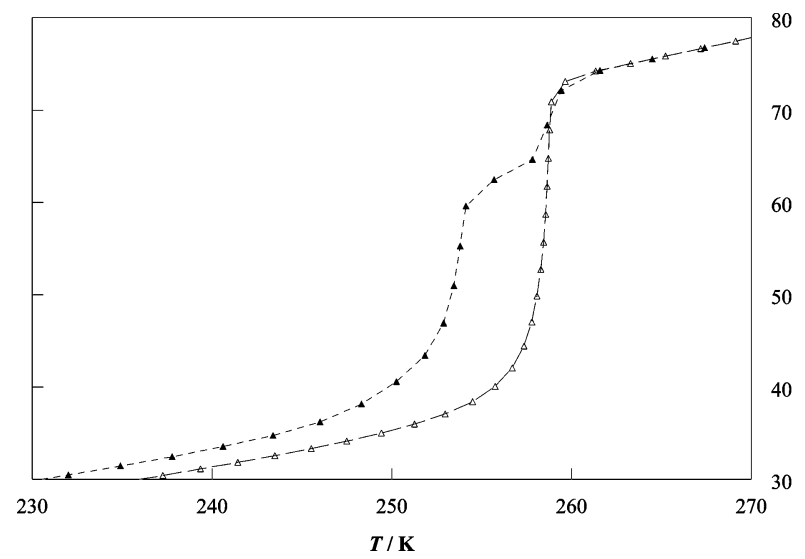

Figure 3. Enthalpy curves of ethyl undecanoate around the melting point: $\Delta$, first run; $\Delta$, second run with the annealed sample.

product had transformed completely to the stable crystalline form. The next measurement was made from $110 \mathrm{~K}$ to $320 \mathrm{~K}$ (series 2 in Table 1 and given in Figure 1). The enthalpy curves of the quenched and the annealed compound are given in Figure 3. The curves were shifted so that the enthalpies in the liquid phase corresponded at $300 \mathrm{~K}$. From the measurement on the annealed sample, the enthalpy of fusion was calculated to be $(36.0 \pm 0.1)$ $\mathrm{kJ} \cdot \mathrm{mol}^{-1}$. The calculation was made between $200 \mathrm{~K}$ and $264 \mathrm{~K}$; the heat capacity of the solid used was $C_{p, \mathrm{~s}}(170 \mathrm{~K}$ to $200 \mathrm{~K})=\{50.45+1.0604 T / \mathrm{K}\} \mathrm{J} \cdot \mathrm{K}^{-1} \cdot \mathrm{mol}^{-1}$, and that of the liquid was $C_{p, 1}(263 \mathrm{~K}$ to $280 \mathrm{~K})=\{323.79+0.3595 \cdot T /$

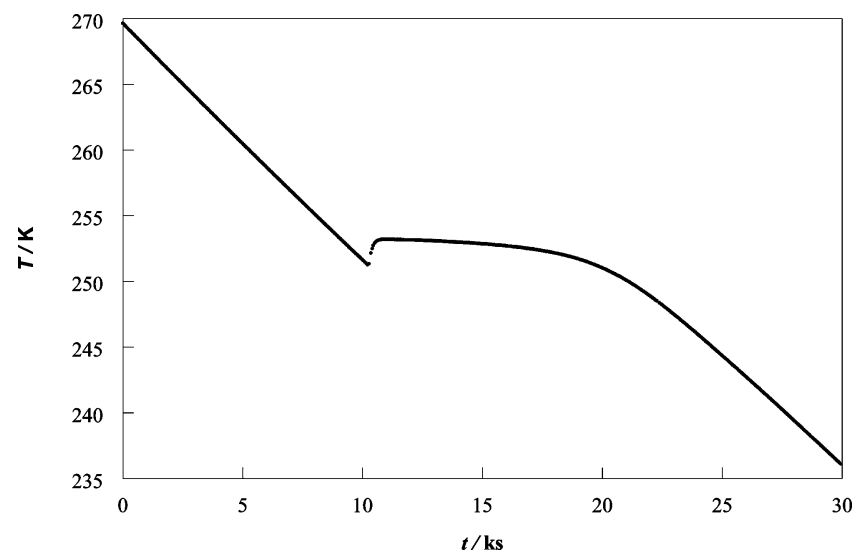

Figure 4. Cooling curve of ethyl undecanoate. Crystallization started at $251.3 \mathrm{~K}$, and the temperature rose to $253.2 \mathrm{~K}$. The cooling rate just before crystallization was $1.8 \times 10^{-3} \mathrm{~K} \cdot \mathrm{s}^{-1}$.

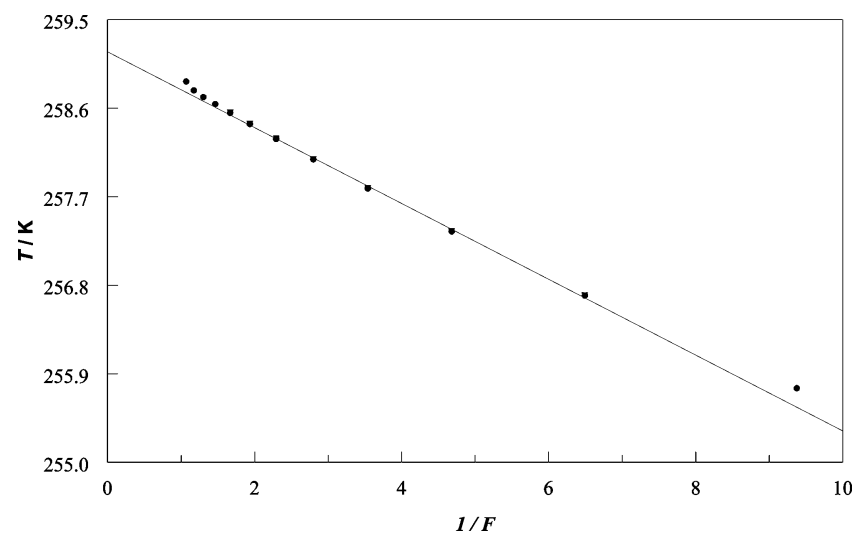

Figure 5. Equilibrium temperature in the melt against the reciprocal of the melted fraction for ethyl undecanoate. $\bullet$, Data points calculated from the run with the annealed sample. Calculated purity, $97.5 \mathrm{~mol} \%$; triple-point temperature, $259.17 \mathrm{~K}$; and enthalpy of fusion, $36.05 \mathrm{~kJ} \cdot \mathrm{mol}^{-1}$.

Table 2. Reciprocal of the Melted Fraction $(1 / F)$ and the Equilibrium Temperatures $\left(T_{\text {eq }}\right)$ in the Melt of Ethyl Undecanoate

\begin{tabular}{cc}
\hline $1 / F$ & $T_{\mathrm{eq}} / \mathrm{K}$ \\
\hline 9.375 & 255.754 \\
6.491 & 256.695 \\
4.680 & 257.347 \\
3.540 & 257.784 \\
2.799 & 258.079 \\
2.294 & 258.287 \\
1.935 & 258.438 \\
1.668 & 258.553 \\
1.464 & 258.642 \\
1.303 & 258.713 \\
1.174 & 258.781
\end{tabular}

$\mathrm{K}\} \mathrm{J} \cdot \mathrm{K}^{-1} \cdot \mathrm{mol}^{-1}$. The enthalpy of fusion was calculated by constructing a sigmoid baseline. In the first calculation, the aforementioned fits were used to calculate the enthalpy increment of the solid and liquid only, thus without the fusion process, the difference in total enthalpy being the first approximation of the enthalpy of fusion. Then the melted fractions were calculated by constructing a new baseline using the contributions of the solid and liquid phases to the heat capacity, and a new enthalpy of fusion was found. This process was repeated until a stable baseline was found. Three iterations were needed. The triple-point temperature was found to be $(259.17 \pm 0.04)$ $\mathrm{K}$, and the calculated purity according to the van't Hoff plot was $97.5 \mathrm{~mol} \%$. The error margin in the triple-point 
Table 3. Experimental Data Series for Ethyl Tridecanoate

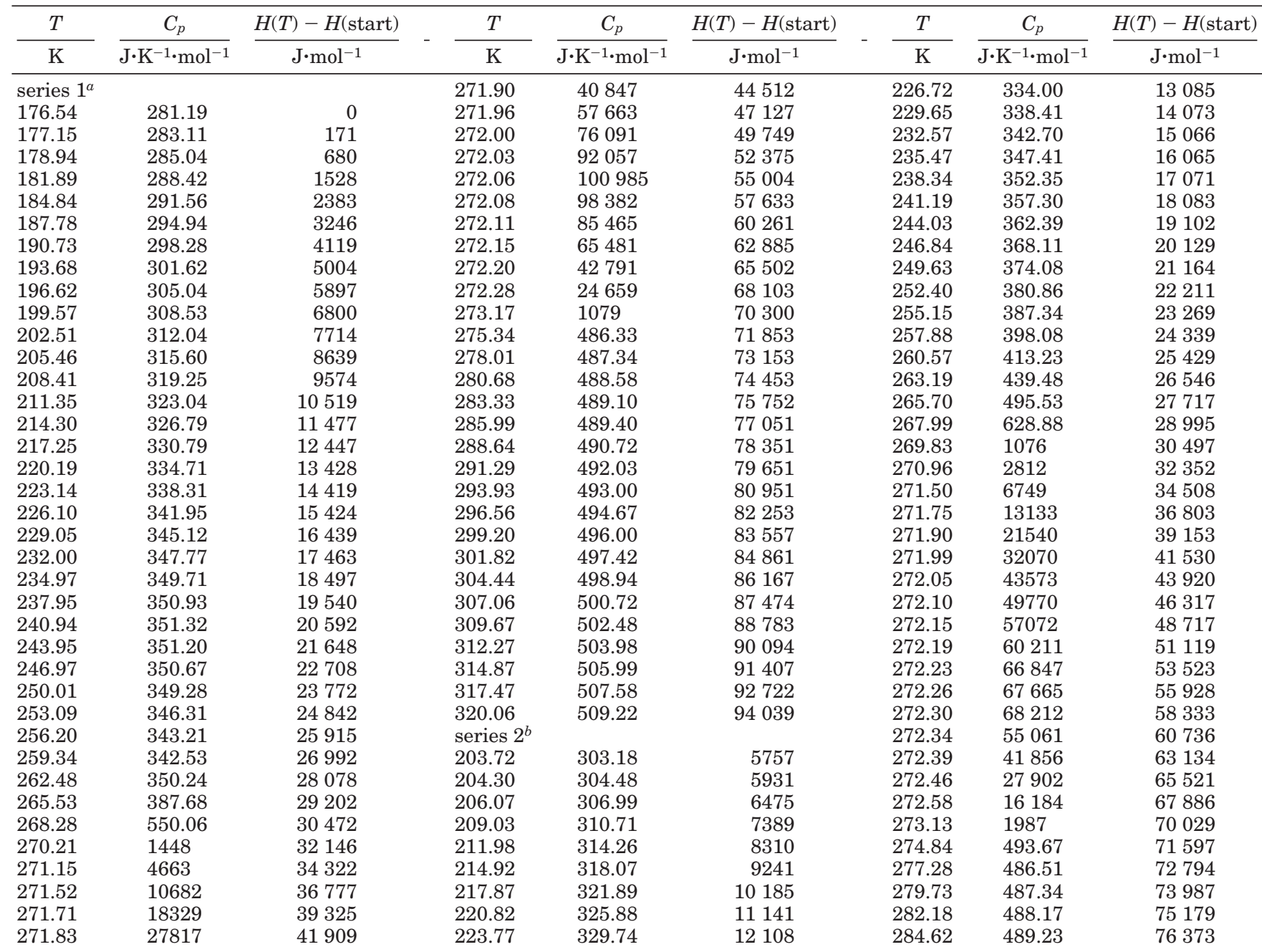

${ }^{a}$ Series 1: Measurement of the metastable crystalline phase to the liquid phase. ${ }^{b}$ Series 2: Measurement of the annealed crystalline phase to the liquid phase.

temperature was taken as twice the standard error calculated for the first coefficient of the linear fit. The small hump around $166 \mathrm{~K}$ is probably due to an impurity and will be the eutectic transition. The heat effect of this transition was not included in the calculation of the enthalpy of fusion. When integrated separately, the enthalpy of transition of the eutectic effect was $108 \mathrm{~J} \cdot \mathrm{mol}^{-1}$. A likely candidate for the impurity is ethanol, whose melting point of $159 \mathrm{~K}$ is close to the transition temperature. This would give an impurity of $0.021 \mathrm{~mol}$ of ethanol in $0.9955 \mathrm{~mol}$ of ethyl undecanoate, leading to a purity for the ethyl undecanoate of $97.9 \mathrm{~mol} \%$, quite close to the measured value. The corrected enthalpy of fusion of ethyl undecanoate than becomes $36.16 \mathrm{~kJ} \cdot \mathrm{mol}^{-1}$. The van't Hoff plot is given in Figure 5; the calculated values of the reciprocal of the melted fraction at the equilibrium temperatures in the melt are given in Table 2. Measurements of the heat capacity of the liquid phase were extended to $365 \mathrm{~K}$ (series 3). Reference 10 gives a value for the melting temperature of the stable phase of $258.5 \mathrm{~K}, 0.7 \mathrm{~K}$ lower than our value. For the metastable phase, a melting temperature of $253.9 \mathrm{~K}$ was reported. This value is close to the crystallization temperature, which we measured to be $253.2 \mathrm{~K}$ (Figure 4). The enthalpy of fusion of the stable phase was given, assuming that the value cited was in $\mathrm{kcal} \cdot \mathrm{mol}^{-1}$, as $31.9 \mathrm{~kJ} \cdot \mathrm{mol}^{-1}$, about $4 \mathrm{~kJ}$ lower than our value. Taking into account that this value was measured
Table 4. Reciprocal of the Melted Fraction $(1 / F)$ and the Equilibrium Temperatures $\left(T_{\text {eq }}\right)$ in the Melt of Ethyl Tridecanoate

\begin{tabular}{cc}
\hline $1 / F$ & $T_{\text {eq }} / \mathrm{K}$ \\
\hline 12.558 & 270.963 \\
7.852 & 271.496 \\
5.520 & 271.752 \\
4.212 & 271.896 \\
3.391 & 271.988 \\
2.834 & 272.052 \\
2.432 & 272.104 \\
2.129 & 272.149 \\
1.893 & 272.190 \\
1.704 & 272.228 \\
1.549 & 272.264 \\
1.420 & 272.299 \\
1.311 & 272.339 \\
1.219 & 272.389 \\
1.138 & 272.460
\end{tabular}

indirectly by using the freezing-point depression, the difference is reasonable.

Ethyl tridecanoate (molar mass $242.4 \mathrm{~g} \cdot \mathrm{mol}^{-1}$ ) was measured in CAL V; $4.4 \mathrm{~g}$ was transferred to the calorimeter vessel in a glovebox under a nitrogen atmosphere. Before closing, the vessel was evacuated, and $1000 \mathrm{~Pa}$ of helium pressure was admitted to enhance the heat transfer in the vessel. The experimental data are given in Table 3. The sample was cooled to $175 \mathrm{~K}$, and a continuous 


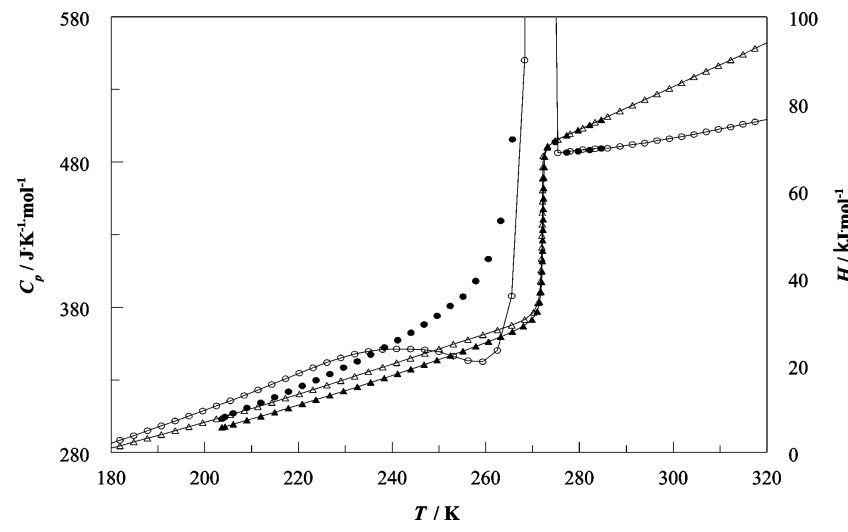

Figure 6. Experimental heat capacity data for ethyl tridecanoate. $\bigcirc$, Heat capacity and $\Delta$, enthalpy of the first measurement. $\bullet$, Heat capacity and $\mathbf{\Lambda}$, enthalpy after relaxation close to the melting point.

measurement to the liquid phase was made. Between $240 \mathrm{~K}$ to $260 \mathrm{~K}$, an exothermic effect took place (Figure 6). Next, the sample was cooled again to $150 \mathrm{~K}$, heated to $269 \mathrm{~K}$, and stabilized overnight at this temperature. Series 2 was measured after cooling the annealed sample to $200 \mathrm{~K}$. No exothermic effects were found in this series.

Calculation of the Enthalpy of Fusion. The calculation was made between $220 \mathrm{~K}$ and $278 \mathrm{~K}$. First the heat capacity of the stable solid phase was fitted between $200 \mathrm{~K}$ and $220 \mathrm{~K}$. This gave $C_{p, \mathrm{~s}}(200 \mathrm{~K}$ to $220 \mathrm{~K})=$ $\{43.85+1.27665 \mathrm{~T} / \mathrm{K}\} \mathrm{J} \cdot \mathrm{K}^{-1} \cdot \mathrm{mol}^{-1}$. The heat capacity of the liquid phase was fitted between $275 \mathrm{~K}$ to $300 \mathrm{~K}$, the fit result being

$$
\begin{aligned}
C_{p, 1}(275 \mathrm{~K} \text { to } 300 \mathrm{~K})= & \\
& \{401.74+0.3079 \mathrm{~T} / \mathrm{K}\} \mathrm{J} \cdot \mathrm{K}^{-1} \cdot \mathrm{mol}^{-1}
\end{aligned}
$$

The enthalpy of fusion was calculated using the same procedure as for ethyl undecanoate. The enthalpy of fusion was found to be $(40.7 \pm 0.1) \mathrm{kJ} \cdot \mathrm{mol}^{-1}$. In Figure 7 , the equilibrium temperatures in the melt are plotted against the reciprocal of the melted fraction. Using the van't Hoff relation for the calculation of the impurity level, thus assuming that the impurity formed an eutectic system with the main component, resulted in a purity of $99.3 \mathrm{~mol} \%$, the triple-point temperature being $(272.4 \pm 0.1) \mathrm{K}$. The assumption that the system is eutectic seems to be reasonable because a large part of the plot in Figure 2 is linear; however, the increase in temperature near the end of the melting process might indicate that the impurity does form a solid solution with the main component. It is for this reason that we have given a larger error margin for the triple-point temperature. The melting temperature of the stable form of ethyl tridecanoate was reported by van Bellinghen ${ }^{10}$ to be $272.3 \mathrm{~K}$, and for the metastable form he found a value of $269.7 \mathrm{~K}$. We did not measure the melting temperature of the metastable phase. For the

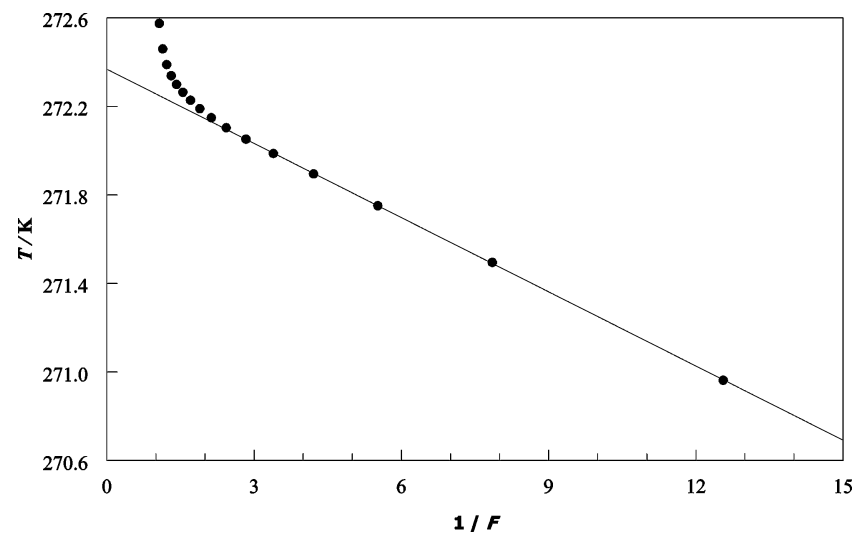

Figure 7. Equilibrium temperature in the melt against the reciprocal of the melted fraction for ethyl tridecanoate. $\bullet$, Data points calculated from the measurement series on the annealed sample. Calculated purity, $99.3 \mathrm{~mol} \%$; triple-point temperature, $272.4 \mathrm{~K}$; and enthalpy of fusion, $40.7 \mathrm{~kJ} \cdot \mathrm{mol}^{-1}$.

enthalpy of fusion of the stable form, he reported $10.20 \mathrm{cal}$; if we assume that this should be kcal, then his value $\left(42.6 \mathrm{~kJ} \cdot \mathrm{mol}^{-1}\right)$, measured indirectly by the use of the freezing-point depression, is close to our value.

\section{Literature Cited}

(1) van Genderen, A. C. G.; van Miltenburg, J. C.; Blok, J. G.; van Bommel, M. J.; van Ekeren, P. J.; van den Berg, G. J.; Oonk, H A. J. Liquid-Vapour Equilibria of the Methyl Esters of Alkanoic Acids: Vapour Pressures as a Function of Temperature and Standard Thermodynamic Functions Changes. Fluid Phase Equilib. 2002, 202, 109-120.

(2) van Bommel, M. J. Thermodynamic Behaviour of Methyl Esters of Long Chain Linear Carboxylic Acids. Thesis, Utrecht University, 1986.

(3) van Miltenburg, J. C.; van den Berg, G. J. K; van Bommel, M. J. Construction of an Adiabatic Calorimeter. Measurements of the Molar Heat Capacity of Synthetic Sapphire and of $n$-Heptane. J. Chem. Thermodyn. 1987, 19, 1129-1137.

(4) van Miltenburg, J. C.; van Genderen, A. C. G.; van den Berg, G. J. K. Design Improvements in Adiabatic Calorimetry. The Heat Capacity of Cholesterol between 10 and 425 K. Thermochim. Acta 1998, 319, 151-162.

(5) Preston-Thomas, H. The International Temperature Scale of 1990 (ITS-90). Metrologia 1990, 27, 3-10.

(6) Douglas, J. P.; Furukawa, G. T.; McCloskey, R. E.; Ball, A. F Calorimetric Properties of Normal Heptane from 0 to $520 \mathrm{~K}$. J. Res. Natl. Bur. Stand. 1954, 53, 139-153.

(7) N.B.S. Standard Reference Material 720, Washington, DC, 1982.

(8) Archer, D. G. Thermodynamic Properties of Synthetic Sapphire $\left(\alpha-\mathrm{Al}_{2} \mathrm{O}_{3}\right)$. Standard Reference Material 720 and the Effect of Temperature-Scale Differences on Thermodynamic Properties J. Phys. Chem. Ref. Data 1993, 6, 1441-1453.

(9) van Miltenburg, J. C.; van den Berg, G. J. K.; van Genderen, A C. G. An Adiabatic Calorimeter for Small Samples. The SolidLiquid System Naphthalene-Durene. Thermochim. Acta 2002 $383,13-19$

(10) van Bellinghen, R. La Congélation des Solutions Comme Méthode d'Investigation de Quelques Problèmes de Chimie Pure. Bull. Soc. Chim. Belg. 1938, 47, 640-688.

Received for review February 14, 2005. Accepted April 11, 2005.

JE050065N 